\title{
Effect of jasmonic acid on cold-storage of Taraxacum pieninicum encapsulated shoot tips
}

\author{
Monika Kamińska ${ }^{1} \cdot$ Andrzej Tretyn $^{1} \cdot$ Alina Trejgell $^{1}$
}

Received: 18 May 2018 / Accepted: 20 August 2018 / Published online: 24 August 2018

(c) The Author(s) 2018

\begin{abstract}
Jasmonic acid is involved in plants response to various abiotic and biotic stresses. The aim of this study was to examine physiological response of Taraxacum pieninicum to JA-treatments during shoots micropropagation and during cold storage at $4{ }^{\circ} \mathrm{C}$ under reduced light or in the darkness. Obtained results indicated that JA during preculture reduced significantly growth of shoots without impact on proliferation rate. During cold storage JA (24-72 $\mu \mathrm{M})$ limited effect of cold stress what was manifested by reduced accumulation of proline and TBARS. Growth inhibition of the stored tissue was more effective when JA was inside synthetic seeds structure than after preculture on medium supplemented with JA. Shoot proliferation and rooting were effective during regrowth after cold storage combined with JA exposure. Only elongation of roots was inhibited after storage in this conditions. However, length of roots did not affect acclimatization of plantlets to ex vitro conditions.
\end{abstract}

Keywords Jasmonic acid $\cdot$ Proline $\cdot$ Shoot proliferation $\cdot$ Slow-growth storage $\cdot$ Taraxacum pieninicum $\cdot$ TBARS

$\begin{array}{ll}\text { Abbreviations } \\ \text { BA } & \text { Benzylaminopurine } \\ \text { JA } & \text { Jasmonic acid } \\ \text { MDA } & \text { Malondialdehyde } \\ \text { MeJA } & \text { Methyl jasmonate } \\ \text { NAA } & \text { Naphthalene acetic acid } \\ \text { TBARS } & \text { Thiobarbituric acid reactive substances }\end{array}$

\section{Introduction}

Cold during storage has a significant impact on a tissue condition. Abiotic stress causes significant reactive oxygen species accumulation, which cause oxidative damage and might result in cell death (You and Chan 2015). Low temperature affects all aspects of cellular function in plants (Yadav 2010; Theocharis et al. 2012). The major adverse effect of cold

Communicated by Klaus Eimert.

Electronic supplementary material The online version of this article (https://doi.org/10.1007/s11240-018-1481-y) contains supplementary material, which is available to authorized users.

Alina Trejgell

trejgell@umk.pl

1 Chair of Plant Physiology and Biotechnology, Nicolaus Copernicus University, Toruń, Poland stress relates to the structure and integrity of the plasma membrane. Lipids containing polyunsaturated fatty acids are well-known targets to the free radicals attacks. Lipid peroxidation leads to the production of many primary products (mainly lipid hydroperoxides $\mathrm{LOOH}$ ), which in further decomposition can form several low-molecular-weight products called thiobarbituric acid reactive substances (TBARS). The most common considered TBARS is malondialdehyde (MDA) which is a mutagen and is widely used as a biomarker for lipid peroxidation of omega-3 and omega- 6 fatty acids (Ayala et al. 2014).

Plants possess cellular mechanisms that limit oxidative damages and increase cold tolerance. The most common strategy is based on accumulation of compatible osmolytes and osmoprotective compounds such as proline (Kishor et al. 2005). Proline has a diverse roles in plants e.g., is involved in stabilizing sub-cellular structures (membranes and proteins) and scavenging free radicals (Hayat et al. 2012). Thus, proline accumulation can effectively overcome lipid peroxidation.

Taraxacum pieninicum belongs to the Asteraceae family and is listed as critically endangered species. In view of its natural occurrence (Pieniny Mts., Poland), this species exhibits a potentially good resistance to cold in a field conditions. Conservation of Taraxacum species is very limited because seeds dramatically lose their vitality after 2 years, thus in vitro culture including storage in a slow growth 
conditions seems to be the most appropriate method of protecting this genus. Synthetic seed technology is useful for plant species which are not able to produce seeds and plants that produce seeds with poor viability (Rihan et al. 2017). Synthetic seeds (synseeds) are defined as artificially encapsulated explants such as shoot tips or nods which possess the ability to convert into a whole plant after storage (Ara et al. 1999). Many gel agents such as agar, carrageenan, guar gum and sodium pectrate were used for encapsulation, although sodium alginate was discovered to be the most suitable and practicable for synseeds production. There are potential advantages of synthetic seed technology such as ease of production and transport. In addition, the use of this technique economizes upon time, space and medium requested by traditional tissue culture (Rihan et al. 2017). In our previous paper, we described efficient storage of T. pieninicum shoot tips and synthetic seeds in in vitro culture (Kamińska et al. 2016, 2018) and the protective effect of alginate coat during cold-storage has been documented. However, shoots overgrown the synseeds structure during storage, what limits the possible time of its storage and protective properties of the alginate coat.

During recent years numerous studies indicated that jasmonic acid (JA) is involved in biotic and abiotic stress response (Koo 2017), developmental processes of plant such as lateral root formation and positioning (Raya-González et al. 2012) but also in age-related leaf senescence (Morquecho-Contreras et al. 2010; Schommer et al. 2008). The aim of our study was to (1) investigate physiological response of $T$. pieninicum to jasmonic acid during shoot proliferation in the optimal growth conditions and during cold storage at $4{ }^{\circ} \mathrm{C}$ under reduced light or in the darkness. and (2) to assess whether jasmonic acid treatment enhance cold tolerance during slow-growth culture.

\section{Materials and methods}

\section{Plant material and culture conditions}

Seeds of T. pieninicum were obtained from the collection of the Polish Academy of Sciences Botanical Garden-Center for Biological Diversity Conservation in Powsin. Initial explants (shoot tips) were isolated from clusters obtained according to Trejgell et al. (2013) and subcultured every 4 weeks on basal MS medium supplemented with $3 \%$ sucrose and $1.1 \mu \mathrm{M}$ BA and $0.14 \mu \mathrm{M}$ NAA. Prior to the addition of $0.8 \%$ agar $(\mathrm{w} / \mathrm{v})$, the $\mathrm{pH}$ of the medium was adjusted to 5.8 before autoclaving. Cultures before storage were kept in continuous white fluorescent light $\left(80 \mu \mathrm{mol} \mathrm{m}^{-2} \mathrm{~s}^{-1}\right)$ at $26 \pm 1{ }^{\circ} \mathrm{C}$ (optimal growth conditions described by Trejgell et al. 2013).

\section{Jasmonic acid treatment}

Two different JA-treatments were examined: (1) 4-weeks preculture in the optimal growth condition on MS medium supplemented with 3\% sucrose, $0.8 \%$ agar and $1.1 \mu \mathrm{M}$ BA and $0.14 \mu \mathrm{M}$ NAA and JA (further indication in the paperpreculture) or (2) jasmonic acid was mixed with the sodium alginate solution (inside) so that it was presented in the synseeds structure during storage. In each treatment four concentrations $(24 \mu \mathrm{M}, 48 \mu \mathrm{M}, 72 \mu \mathrm{M}, 96 \mu \mathrm{M})$ of JA were tested. After preculture proliferation rate (number of shoots per explant) was additionally evaluated.

\section{Synthetic seeds production}

For encapsulation shoot tips of T. pieninicum were obtained from 4-week in vitro culture with or without JA. Isolated shoot tips were suspended in 3\% Na-alginate prepared in liquid MS medium. The shoot tips covered with alginate were dropped individually into $100 \mathrm{mM} \mathrm{CaCl} \cdot 2 \mathrm{H}_{2} \mathrm{O}$ and kept for $25 \mathrm{~min}$ for polymerization. Thereafter, beads were retrieved from the calcium chloride solution using sterile sieve and washed with sterile distilled water.

\section{Cold storage conditions}

The synthetic seeds were transferred into Magenta ${ }^{\circledR}$ box containing $50 \mathrm{ml}$ MS medium supplemented with 3\% sucrose, $0.8 \%$ agar, without plant growth regulators (except JA in inside treatment) and stored under reduced continuous white fluorescent light $\left(40 \mu \mathrm{mol} \mathrm{m}{ }^{-2} \mathrm{~s}^{-1}\right)$ or in the darkness at $4 \pm 1^{\circ} \mathrm{C}$ for 3,6 and 9 months. Synthetic seeds non-treated with JA were used as control.

\section{Post-storage regrowth}

After storage the alginate coat was removed and shoot tips from converted plants were transferred on fresh MS medium with full-strength nutrients supplemented with $3 \%$ sucrose, $1.11 \mu \mathrm{M}$ BA, $0.14 \mu \mathrm{M}$ NAA and $0.8 \%$ agar in the optimal growth conditions and subcultured twice. The proliferation rate was evaluated after each 4-week subculture.

For acclimatization the obtained shoots were rooted on MS medium without plant hormones. Ability of shoots to form roots was investigated on the base of roots number per shoot and root length. Formed roots were gently washed with sterile water to remove residual MS medium. Plantlets were then transplanted to plastic pots containing autoclaved mixture of vermiculite and sand $(1: 1 \mathrm{v} / \mathrm{v})$, covered with a transparent boxes to maintain humidity (60-70\%) and kept in a growth chamber at $23 \pm 1{ }^{\circ} \mathrm{C}$ with white fluorescent 
illumination $\left(80 \mu \mathrm{mol} \mathrm{m} \mathrm{m}^{-2} \mathrm{~s}^{-1}\right)$. Plants were subsequently transferred to the pots containing sterile soil and then were transferred to the field conditions. Each step of the acclimatization was carried out after 4 weeks.

\section{Biochemical analyses}

Free proline determination was evaluated directly after coldstorage and after 1st subculture in the optimal conditions as described by Bates et al. (1973). Each sample contained about $50 \mathrm{mg}$ tissue. Membrane lipid peroxidation was measured by the amount of TBARS. TBARS concentration was estimated directly after cold-treatment, following the protocol described by Song et al. (2011).

\section{Data collection and statistical analysis}

Proliferation rate after preculture with JA was evaluated for 8 explants. Stored microshoots were evaluated at 3 month intervals. In each variant of storage 16 encapsulated shoot tips were used. Proliferation rate in 1 st subculture was obtained for shoots that survived the cold treatment for 3 , 6 and 9 months. Proliferation rate in 2nd subculture and rooting rate were evaluated for 8 explants. Three replicates were performed for each analysis. Data were expressed as mean \pm standard error (SE). Normality of variances was verified using the Shapiro-Wilk test. To examine significant differences among the treatments Kruskal-Wallis test at $\mathrm{p} \leq 0.05$ was then performed, because of a non-normal data distribution and unequal sample sizes in post-regrowth part. Biochemical analyses were carried out in three replicates of the independent plants tissues and statistically significant differences were assess using Tukey's multiple range test at $\mathrm{p}<0.05$.

\section{Results}

\section{Preculture with JA in optimal conditions}

Before cold storage explants in the first JA-treatment were propagated for 4 weeks on MS medium supplemented with BA, NAA and JA. Obtained results indicated that shoots cultured on medium with JA added in the lowest concentration $(24 \mu \mathrm{M})$ had the highest proliferation rate $(26.7 \pm 2.5$ axillary shoots per explant) but the difference to the control plants $(18.9 \pm 2.2)$ was not statistically significant (Fig. 1a, b). The lowest proliferation rate $(11.5 \pm 1.2)$ was noted for the medium supplemented with the highest used concentration of JA $(96 \mu \mathrm{M})$ and the difference in comparison to other concentration was significant. Increasing JA concentration led to limiting growth of the shoots. In addition, shoots on medium with JA in the highest used concentration were fragile with easily falling

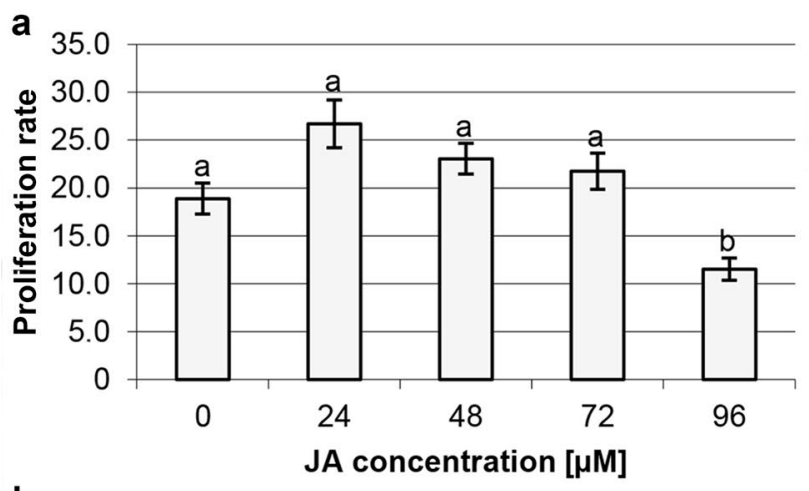

b

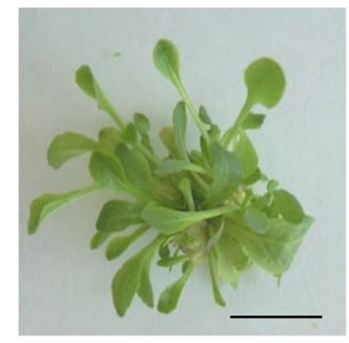

Control

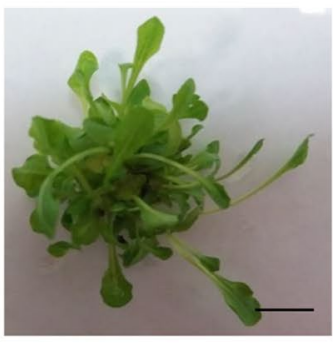

$24 \mu \mathrm{M}$ JA

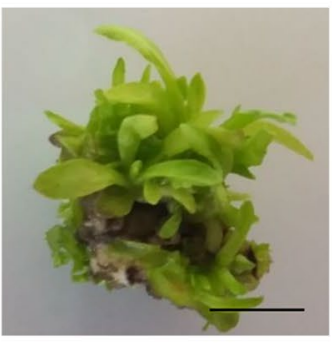

$48 \mu \mathrm{M} J A$

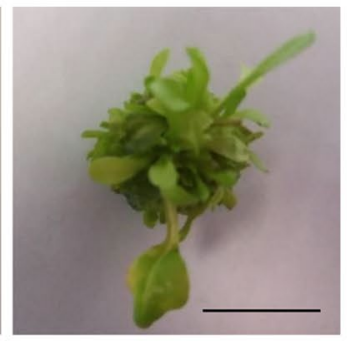

$72 \mu \mathrm{M}$ JA

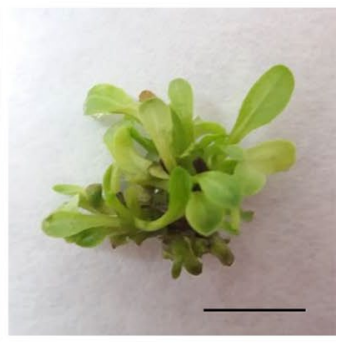

$96 \mu \mathrm{M} J \mathrm{~A}$
Fig. 1 The effect of JA on shoot proliferation of Taraxacum pieninicum in the optimal growth conditions: proliferation rate (a) and phenotype of shoots clusters (b) on MS medium supplemented with
1.11 $\mu \mathrm{M}$ BA and $0.14 \mu \mathrm{M}$ NAA and different concentration of JA after 4 weeks of the culture. Bar $=1 \mathrm{~cm}$. Means with different letters are significantly different followed by Kruskal-Wallis test at $\mathrm{p} \leq 0.05$ 
leaves. Furthermore, on the medium containing JA alone multiplication was not observed (data not shown).

\section{Regrowth of stored plants under optimal conditions}

Synthetic seeds in both JA-treatments showed reduced growth in comparison to the control plants during coldstorage. JA decreased leaf blade size in plants stored under light conditions (Fig. 2a). In turn, in the darkness exposure to JA in both treatments resulted in inhibition of leaf elongation but blade size slightly increased (Fig. 2b).

During regrowth, comparing to the control plants JA did not affect significantly shoots ability to proliferate in the 1 st subculture in most treatments after 9 months of storage (Fig. 3a). Only for the explants with JA $24 \mu \mathrm{M}$ inside synseed structure stored in darkness statistically significantly higher proliferation rate $(20.9 \pm 1.4$ shoots per explant) was noted than for the control plants $(15.1 \pm 1.8$ shoots per explant). Comparing treatments, it was noted that $24 \mu \mathrm{M}$ and $96 \mu \mathrm{M} \mathrm{JA}$ inside synseed structure resulted in a significantly lower ability of shoots to proliferate after storage under light conditions than preculture with the same JA concentrations. Statistically significant differences between light conditions were observed for the control, for preculture with $24 \mu \mathrm{M} \mathrm{JA}$ and for the highest JA concentration in both treatments, regardless of the storage duration (Fig. 3a, Supplement 1).

In the 2nd subculture plants from inside JA-treatment and plants precultured with $24 \mu \mathrm{M}$ JA showed reduced ability to proliferate (Fig. 3b). The inhibitory effect of JA was not recorded for shorter storage period ( 3 and 6 months) and even stimulation of the shoot proliferation was observed in the plants precultured with $24 \mu \mathrm{M} \mathrm{JA}$ (Supplement 2). Negative effect caused by light persisted also in the 2nd subculture.

JA in both treatments did not affect significantly rooting ability of shoots and number of roots per shoots after post-storage regrowth on MS medium without plant regulators, regardless of the storage time (Fig. 4a, b, Supplement 3,4). However, after 9 months of storage inhibition of root elongation was observed for all JA treatments, except of $24 \mu \mathrm{M}$ JA inside synseeds in both light conditions (Fig. 4c). After 3 months of storage, there was no inhibition of root growth (Supplement 5a), while after 6 months shorter roots were reported in the plants from JApreculture treatment and in the variant with the highest used concentration of JA inside synseeds (Supplement 5b).

Obtained plantlets regardless of the JA-treatment, light conditions and duration of storage were successfully acclimatized and did not show any phenotypic changes to nonstored microcuttings (Fig. 5).

\section{Biochemical analyses}

In the optimal growth conditions, before cold-treatment, proline was accumulated on low level $(1.3 \pm 0.1 \mathrm{mg} / \mathrm{g}$ fresh weight) in T. pieninicum shoots (Fig. 6). JA-preculture did not affect proline accumulation, except for the highest JA concentration. Shoots precultured on MS medium supplemented with $96 \mu \mathrm{M} \mathrm{JA}$ contained $2.2 \pm 0.1 \mathrm{mg}$ proline/g FW. Cold storage generally stimulated biosynthesis of proline in all used variants (Fig. 7a). JA-preculture reduced accumulation of proline in shoots stored under light conditions, although significant difference to the control plants was reported only after preculture on medium MS with $24 \mu \mathrm{M}$ JA. While the highest used concentration $(96 \mu \mathrm{M})$ did not affect proline content in shoots in comparison to the control plants in both light conditions. Slightly more proline was accumulated during storage under light conditions in each treatment. However, statistically significant difference between light conditions was observed for the control and for the plants precultured with $96 \mu \mathrm{M}$. Similar data were recorded after 3 and 6 months storage (Supplement 6).

After 1st passage in the optimal growth conditions amount of accumulated proline decreased markedly. The highest proline level was noted in the shoots of plants stored under light conditions after preculture on $96 \mu \mathrm{M} \mathrm{JA}$ (Fig. 7b). Similar results were noted for material stored for 3 and 6 months (Supplement 7).

Prolonged storage time enhanced production of TBARS in the control plants under light conditions (Fig. 8). In the plants precultured on medium supplemented with JA it was reported that the highest used concentration increased TBARS content under light conditions, regardless of the storage duration (Supplement 8). In inside JA-treatment, the TBARS content decreased with increasing concentration of JA under light conditions. Furthermore, it was reported that JA decreased TBARS content in comparison to the control after storage in the dark lasting more than 3 months, regardless of the treatment and JA concentration.

\section{Discussion}

JA-like compounds occur widely in the plants, with highest activities in growing tissue such as stem apex, young leaves, immature fruits, and root tips (Sembdner and Parthier 1993).

Many studies showed that the effect of JA on growth and proliferation of plants in in vitro culture strictly depends of its concentration in the medium. In nanomolar range JA increased the explant size and the number of leaves in nodal explants of cabbage (Toro et al. 2003). JA added in concentrations from 0.01 to $1 \mu \mathrm{M}$ increased the number and length of nodes of grapevine and potato, but the opposite effect was observed above this range (Ravnikar et al. 1990). 
a
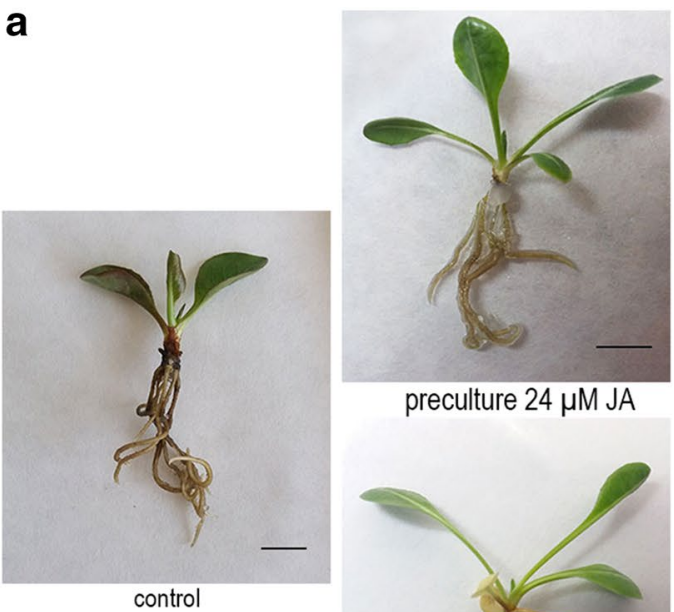

preculture $24 \mu \mathrm{M} \mathrm{JA}$

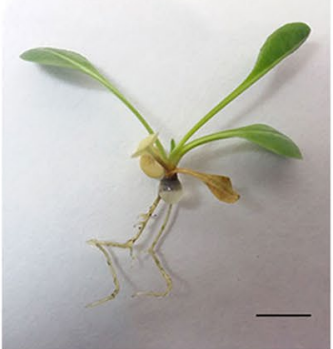

inside $24 \mu \mathrm{M} \mathrm{JA}$

b

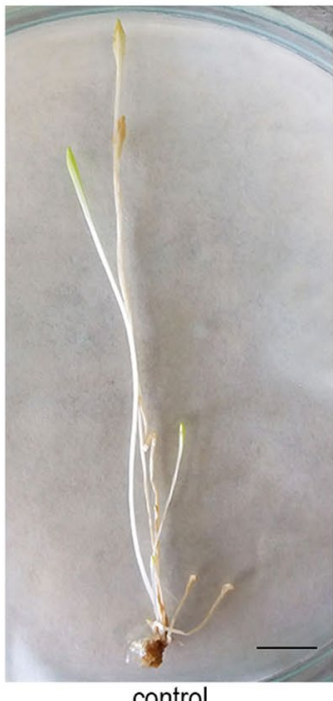

control

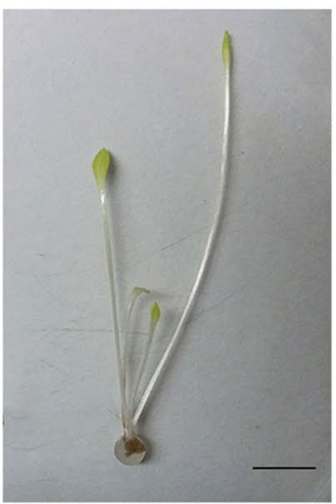

preculture $24 \mu \mathrm{M} \mathrm{JA}$

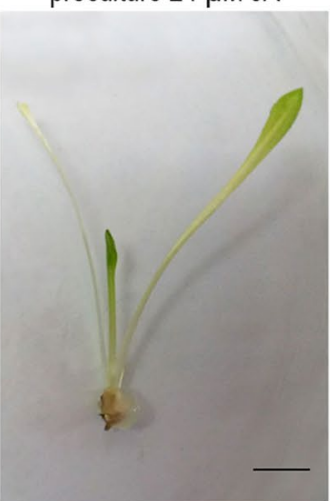

inside $24 \mu \mathrm{M} \mathrm{JA}$

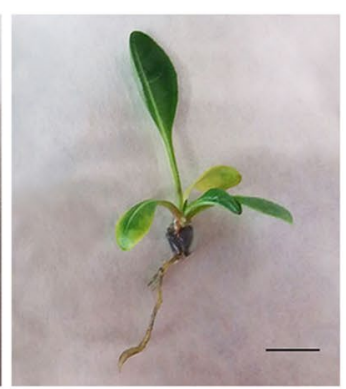

preculture $48 \mu \mathrm{M} \mathrm{JA}$

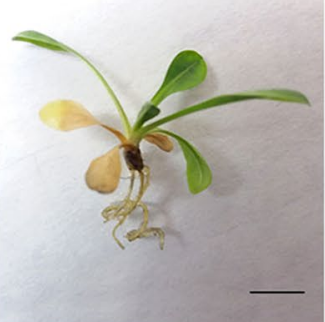

inside $48 \mu \mathrm{M} \mathrm{JA}$

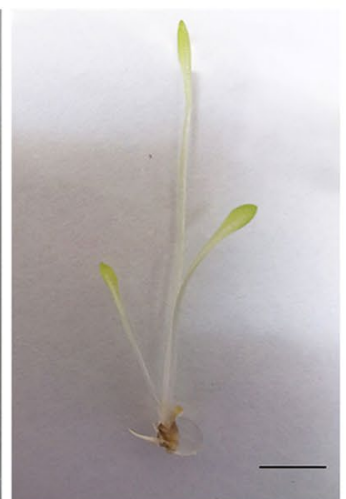

preculture $48 \mu \mathrm{M} \mathrm{JA}$

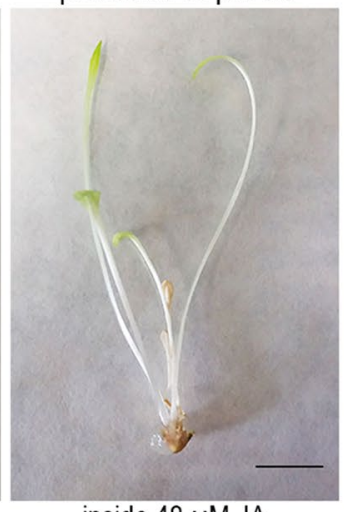

inside $48 \mu \mathrm{M} \mathrm{JA}$

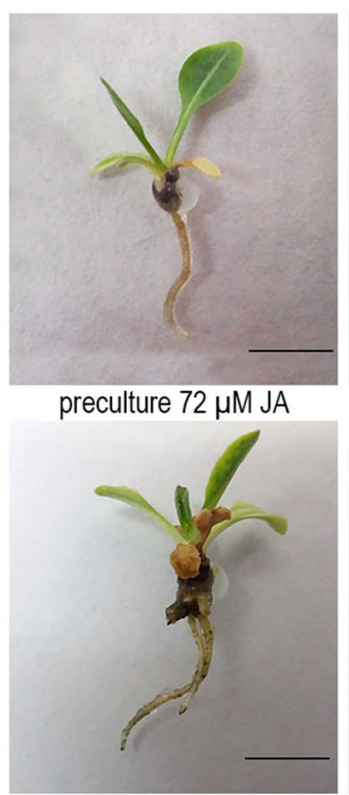

inside $72 \mu \mathrm{M} \mathrm{JA}$

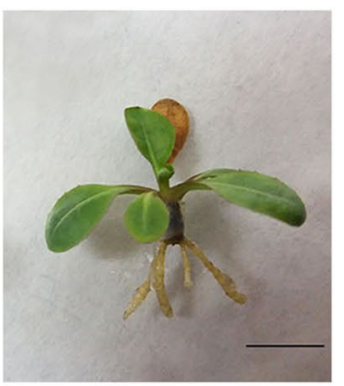

preculture $96 \mu \mathrm{M} \mathrm{JA}$

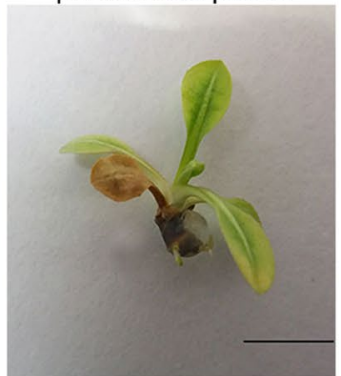

inside $96 \mu \mathrm{M} \mathrm{JA}$

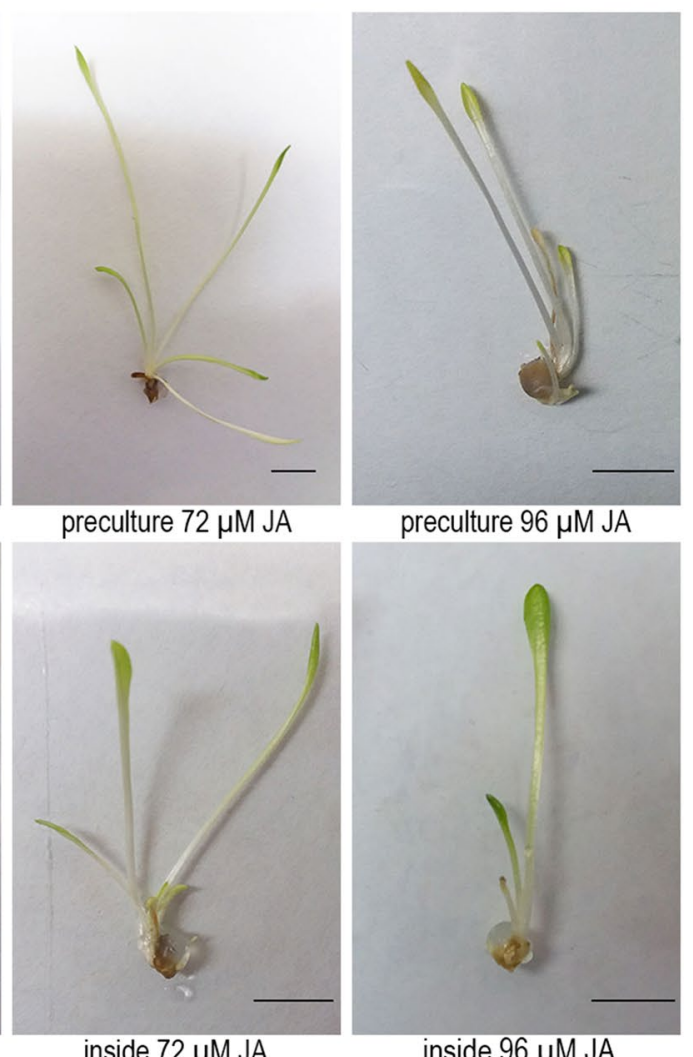

Fig. 2 Shoots converted from synthetic seeds during 9 months storage at $4{ }^{\circ} \mathrm{C}$ under light conditions (a) and in the darkness (b) after different treatment with JA. Bar $=1 \mathrm{~cm}$

Furthermore, in lower concentration in the case of potato stem node culture stimulatory effect on the shoot length was observed. Addition of JA at higher concentration than $10 \mu \mathrm{M}$ resulted in stunted plantlets without impact on the number of nodes (Ravnikar et al. 1992). Treatment with JA in concentration also up to $10 \mu \mathrm{M}$ led to formation of plantlets 


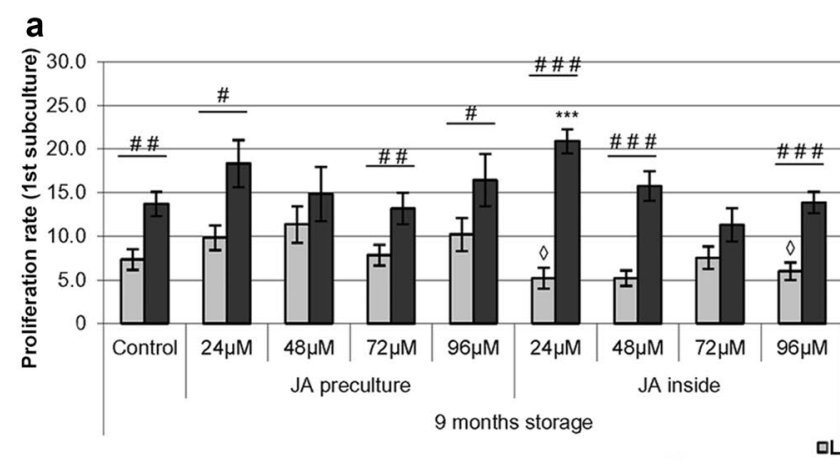

Fig. 3 The effect of light conditions and JA-treatment on Taraxacum pieninicum proliferation rate of shoots during regrowth on MS medium with $1.11 \mu \mathrm{M}$ BA and $0.14 \mu \mathrm{M}$ NAA in the 1 st (a) and 2nd (b) subculture after 9 months storage at $4{ }^{\circ} \mathrm{C}$. Statistically significant differences assessed using Kruskal-Wallis test at $p \leq 0.05$ : to

with larger leaf surface and thicker stems in potato (MartínClosas et al. 2000), pear and cherry cultures (Ružić et al. 2013) and to enhancement of the garlic shoots and bulbs development (Ravnikar et al. 1993). In Pistacia vera optimal concentration of MeJA for shoot multiplication was $1 \mu \mathrm{M}$. Higher concentration $(10 \mu \mathrm{M})$ led to the leaf senescence and decrease in shoots ability to proliferate (Dolcet-Sanjuan and Claveria 1995). Our results indicated that increasing concentration of JA in the proliferation medium significantly limited the size of the plants what is highly desirable during long storage of a plant material in slow growth conditions. It was also noted that ability of the explants to proliferate decreased in the highest used concentration $(96 \mu \mathrm{M})$. Similar results were obtained for JA-treated rice seedlings which growth was inhibited with increasing concentration up to $50 \mu \mathrm{M}$ of JA in the MS medium (Cho et al. 2007). The effect of JA in represing shoot and root growth may be related to both cell division and elongation program, which may result from inhibition of the synthesis of the cell wall polysaccharides and reduction in mitotic activity in the meristem (Miyamoto et al. 1997; Raya-González et al. 2012).

On the basis of many observations, it was concluded that JA and its derivatives (MeJA and dihydro-MeJA) stimulate the induced systemic resistance (ISR), which improve production of stress and disease tolerance (Ghasemi Pirbalouti et al. 2014). Jasmonates are key signaling compounds in plant responses to biotic and abiotic stresses as well as in development. JA is involved in response to desiccation, ozone, UV, osmotic, cold and light stresses (Wasternack 2014). Under cold stress amount of endogenous JA increase in different plant species including rice (Du et al. 2013), wheat (Kosová et al. 2012) and Arabidopsis thaliana (Hu et al. 2013). Application of MeJA improves cold storage of subtropical fruits, e.g. mango (González-Aguilar et al. 2000) and lemon (Siboza et al. 2014) by reducing chilling injury.

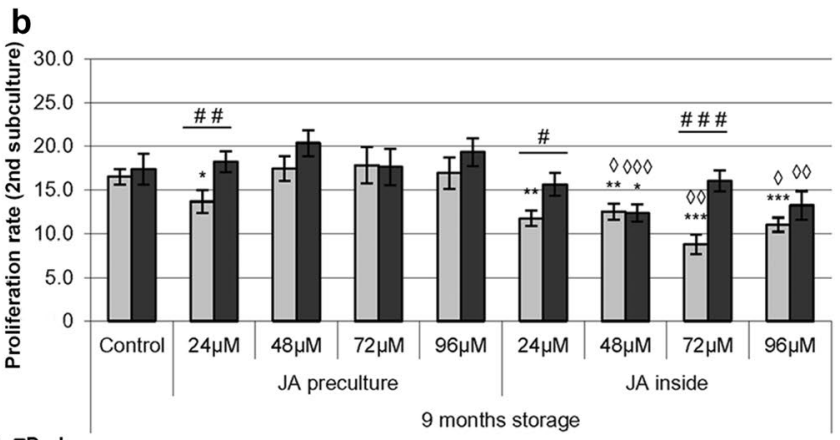

the control plants in the same light conditions are denoted $* \mathrm{p}<0.05$, $* * \mathrm{p}<0.01, * * * \mathrm{p}<0.001$; between light conditions are denoted ${ }^{\#} \mathrm{p}<0.05,{ }^{\# \#} \mathrm{p}<0.01,{ }^{\# \#} \mathrm{p}<0.001$; between JA treatment in the same light conditions are denoted $\diamond_{\mathrm{p}}<0.05, \diamond \diamond_{\mathrm{p}}<0.01, \diamond \diamond \diamond_{\mathrm{p}}<0.001$

Our study shown that JA application before cold-storage (preculture) or inside synthetic seeds reduce significantly growth of plantlets during storage. In addition, we reported stimulatory effect of JA-treatments (both type) on proliferation rate during regrowth, which indicated better condition of the stored material comparing to the control plants. Similar as in previously studies (Kamińska et al. 2016, 2018) higher proliferation rate of shoots was observed after storage in the darkness than under light conditions.

Effect of JA and its derivatives on rooting of plant is better documented. The ability to form roots is controlled by multiple endogenous and environmental factors, among which auxins plays the most important role (Gutierrez et al. 2012). It is well documented that auxin biosynthesis can be induced by jasmonate and vice versa. Furthermore, jasmonates increase local auxin accumulation in the basal meristem, essential for lateral root formation (Sun et al. 2009). Low concentration of JA and MeJA inhibited primary root growth and promoted lateral root formation in Arabidopsis (Wang et al. 2002; Woodward and Bartel 2005; Sun et al. 2009; Raya-González et al. 2012) and decreased adventitious rooting in Arabidopsis hypocotyls (Gutierrez et al. 2012). Our results indicated that JA exposure during cold-storage did not affect shoots ability to form roots and number of roots per shoot during regrowth. However, JA indirectly decreased adventitious root length after 9 months storage regardless of the JA-treatment (preculture or inside synseeds). Similar but directly effect was observed in Pistacia vera rooted on medium supplemented with MeJA (DolcetSanjuan and Claveria 1995).

Enhanced accumulation of proline in plants tissue under different abiotic stress, including cold, is well documented. Proline increased in Triticum aestivum after 1 week of cold acclimation $\left(3{ }^{\circ} \mathrm{C}\right)$ (Kamata and Uemura 2004) and in Cucurbita pepo after 2 weeks at $4{ }^{\circ} \mathrm{C}$ in (Carvajal et al. 
Fig. 4 The effect of light conditions and JA-treatment on Taraxacum pieninicum rooting ability of shoots on MS medium after 9 months storage at $4{ }^{\circ} \mathrm{C}$ assessed by $\%$ of rooted shoots (a), number of roots per rooted shoots $(\mathbf{b})$ and length of roots $(\mathbf{c})$. Statistically significant differences assessed using Kruskal-Wallis test at $\mathrm{p} \leq 0.05$ : to the control plants in the same light conditions are denoted $* \mathrm{p}<0.05$, $* * \mathrm{p}<0.01, * * * \mathrm{p}<0.001$ between light conditions are denoted $^{\#} \mathrm{p}<0.05,{ }^{\# \#} \mathrm{p}<0.01$, $\# \#$ $\mathrm{p}<0.001$; between JA treatment in the same light conditions are denoted $\diamond_{\mathrm{p}}<0.05$, $\diamond \diamond_{\mathrm{p}}<0.01, \diamond \diamond \diamond_{\mathrm{p}}<0.001$
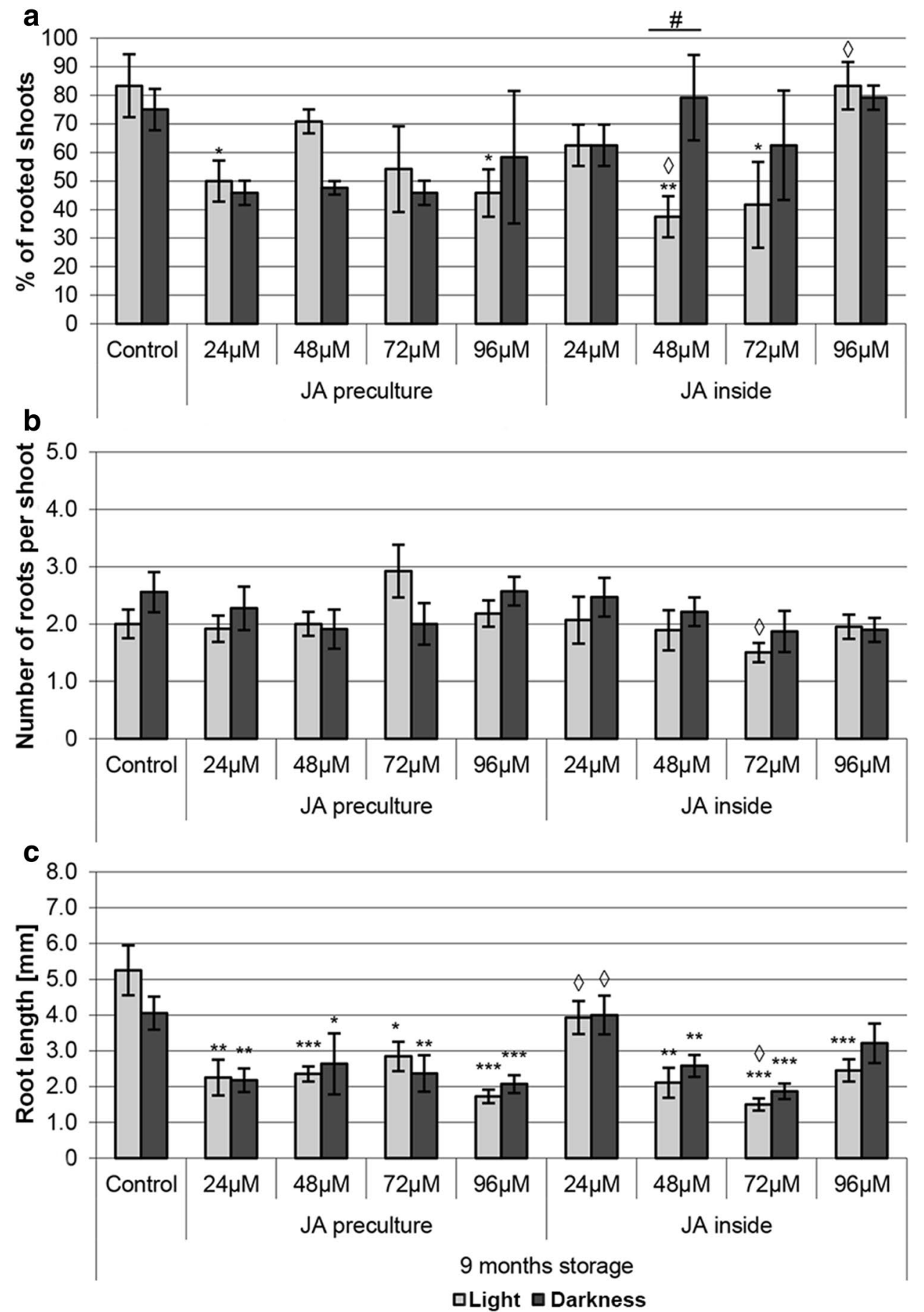

2015). Although in A. thaliana and Vitis vinifera proline level increased after only $4 \mathrm{~h}$ at $4{ }^{\circ} \mathrm{C}$ (Kaplan et al. 2007; Rooy et al. 2017). During first few weeks of storage of Prunus persica mesocarp at $0{ }^{\circ} \mathrm{C}$ and Mangifera indica at $10{ }^{\circ} \mathrm{C}$ proline content increased and decreased slightly afterwards (Shan et al. 2016; Li et al. 2014). In this study cold stress increased amount of proline almost 20-folds after 3 months and did not significantly change after longer storage. Furthermore, higher proline content was reported in the plants stored under light conditions than in the darkness.

The effect of JA on proline content depends on its concentration and plant species. In Hordeum spontaneum no significant differences were observed after exposure on 5 and $15 \mu \mathrm{M} \mathrm{JA}$, but in $H$. vulgare application of $15 \mu \mathrm{M}$ JA decreased proline content (Bandurska et al. 2003). However, Maslenkova et al. (1992) in studies on H. vulgare seedlings indicated increased proline content with 
Fig. 5 Plantlets obtained after cold-storage acclimatized in mixture of vermiculite and sand after 9 months storage at $4{ }^{\circ} \mathrm{C}$ and regrowth in the optimal growth conditions. Control without cold-storage
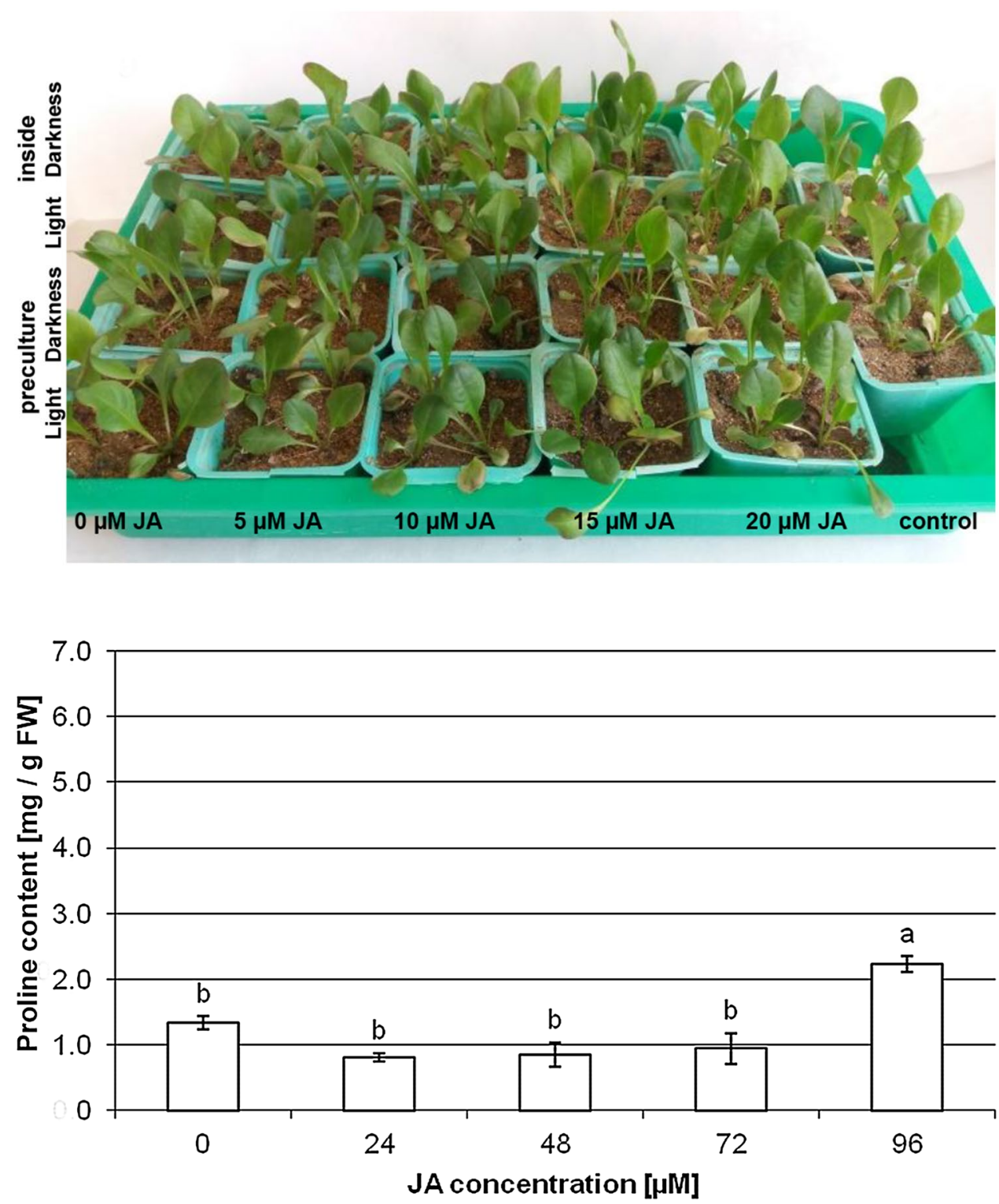

Fig. 6 Proline content in shoots after 4-week preculture on medium MS supplemented with $1.11 \mu \mathrm{M}$ BA and $0.14 \mu \mathrm{M}$ NAA and different concentration of JA. Means with different letters are significantly different followed by Tukey test at $\mathrm{p} \leq 0.05$
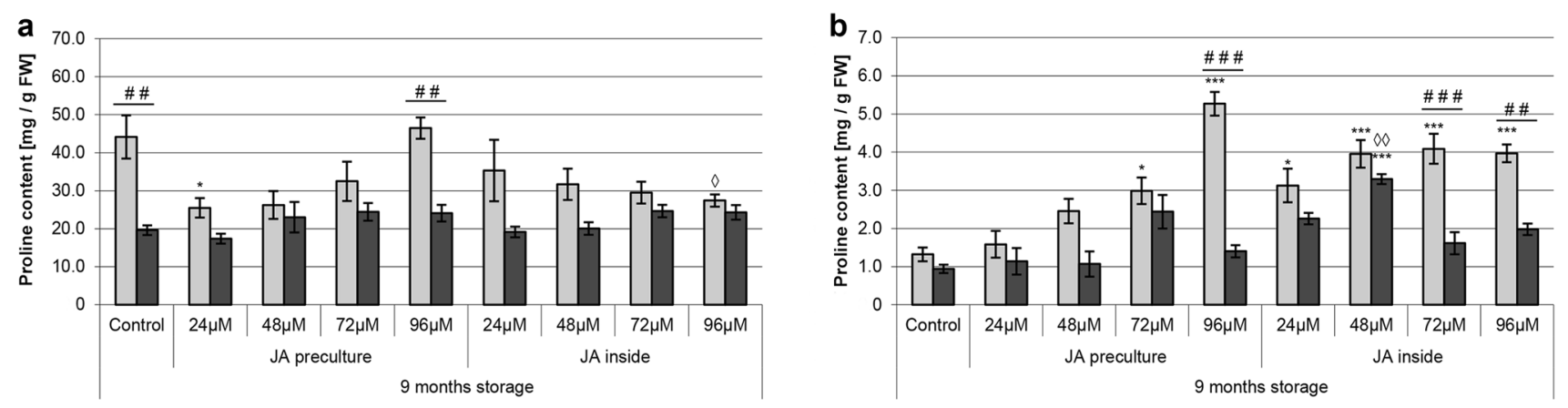

口Light םDarkness
Fig. 7 The effect of light conditions and JA-treatment on accumulation of proline in Taraxacum pieninicum shoots directly after 9 months storage at $4{ }^{\circ} \mathrm{C}$ (a) and after 1st subculture on MS medium with $1.11 \mu \mathrm{M}$ BA and $0.14 \mu \mathrm{M}$ NAA in the optimal growth conditions (b). Statistically significant differences assessed using Tukey test at $\mathrm{p} \leq 0.05$ : to the control plants in the same light conditions are denoted $* \mathrm{p}<0.05, * * \mathrm{p}<0.01, * * * \mathrm{p}<0.001$; between light conditions are denoted ${ }^{\#} \mathrm{p}<0.05,{ }^{\# \#} \mathrm{p}<0.01,{ }^{\# \# \#} \mathrm{p}<0.001$; between JA treatment in the same light conditions are denoted $\diamond_{\mathrm{p}}<0.05, \diamond \diamond_{\mathrm{p}}<0.01$, $\diamond \diamond \diamond_{\mathrm{p}}<0.001$ 
Fig. 8 The effect of light conditions and JA-treatment on accumulation of TBARS in Taraxacum pieninicum shoots after 9 months storage at $4{ }^{\circ} \mathrm{C}$. Statistically significant differences assessed using Tukey test at $p \leq 0.05$ : to the control plants in the same light conditions are denoted $* \mathrm{p}<0.05$, $* * \mathrm{p}<0.01, * * * \mathrm{p}<0.001$; between light conditions are denoted ${ }^{\#} \mathrm{p}<0.05,{ }^{\# \#} \mathrm{p}<0.01$, $\# \#$ p $<0.001$; between JA treatment in the same light conditions are denoted $\diamond_{\mathrm{p}}<0.05$, $\diamond \diamond_{p}<0.01, \diamond \diamond \nabla_{p}<0.001$

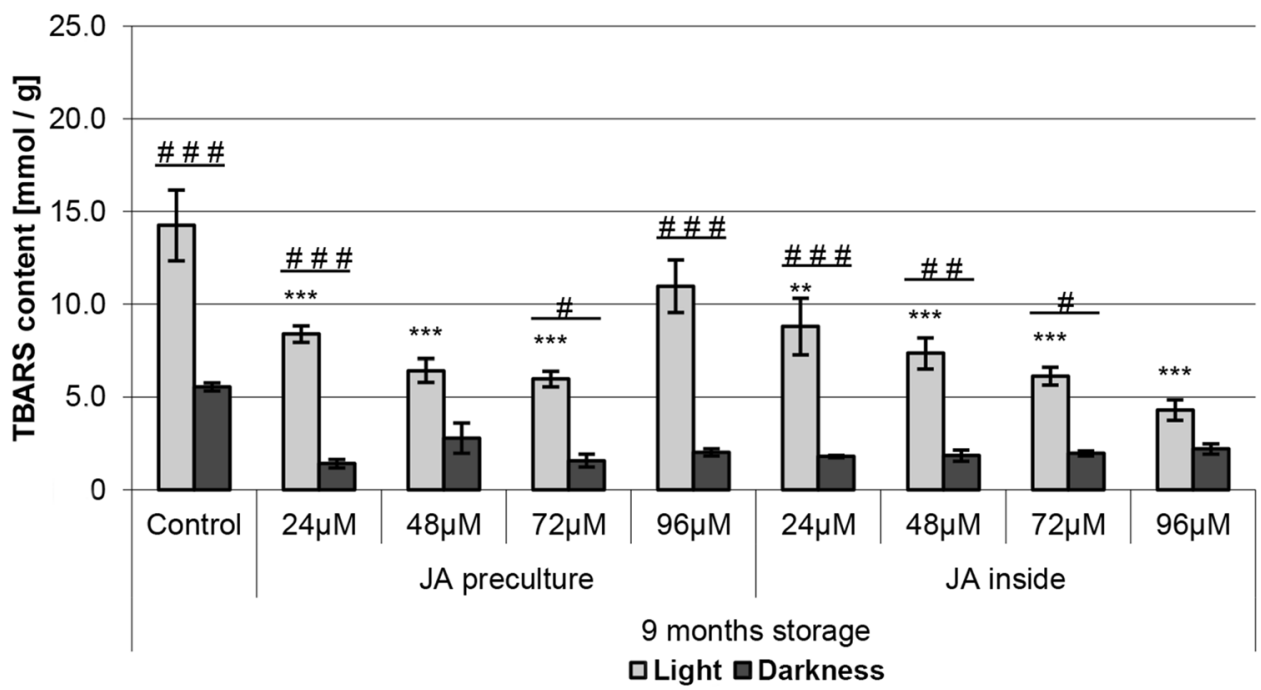

increasing JA concentration $(2.5-250 \mu \mathrm{M})$. In our study JA did not affect significantly proline accumulation in the stored explants compared to non-treated plants, except for preculture on $96 \mu \mathrm{M}$ JA. No increase of proline content was also observed in rice leaves exposed to MeJA in the darkness and in light conditions (Chen et al. 1994).

Some studies indicate that lipid peroxidation in cell membranes, expressed as MDA content, can be activated by the action of lipoxygenase, which is stimulated by jasmonates (Piotrowska et al. 2010). In the present study TBARS content in the plant tissue, as indices of damage, increased more noticeably during storage under light conditions than in the darkness. Furthermore, prolonging storage time resulted in increase of TBARS content under light conditions, but decreased in the darkness. Preculture before storage on medium supplemented with 24-72 $\mu$ M JA decreased production of TBARS under light conditions. In higher concentration $(96 \mu \mathrm{M})$ amelioration of a cold stress was not observed what correlates with results obtained during post-storage shoots proliferation and proline accumulation. These results are in agreement with Piotrowska et al. (2010), where JA in low concentration $(0.01-0.1 \mu \mathrm{M})$ directly stimulated increase in fresh weight and decrease in TBARS production in aquatic plant Wolffia arrhiza, but above this concentration $(10-100 \mu \mathrm{M}) \mathrm{JA}$ reduced plants growth and stimulated formation of lipid peroxides. In turn, JA in higher concentration effectively ameliorated drought stress in Brassica seedlings (2000 $\mu \mathrm{M} \mathrm{JA})$ and salt stress in wheat (500 $\mu \mathrm{M} \mathrm{JA})$ through a significant reduction in MDA content (Alam et al. 2014; Qiu et al. 2014). Furthermore, in our study, when JA was inside synseed structure, TBARS content decreased with increasing JA concentration under light conditions.

\section{Conclusions}

In conclusion, the results indicated that exogenous application of JA slightly induced cold tolerance by decrase in TBARS level, but did not induced proline accumulation during T. pieninicum storage in the slow-growth conditions. Moreover, JA inhibited overgrowing the synseeds structure during storage what may extend the protective effect of the alginate coat and thus extend time of synseeds storage. Inhibition of the tissue growth was more effective when JA was inside synthetic seeds structure than after preculture on medium supplemented with JA. Furthermore, limited growth during storage did not affect quality of the stored material in post-storage regrowth.

Acknowledgements This project was supported by fund from Ministry of Science and Higher Education (PL) for Nicolaus Copernicus University in Toruń, including a grant for young scientist (MK) Number 2827-B.

Author contributions MK designed and carried out all the experiments, analysed the data and wrote the manuscript, AT helped in analysis of the data and in writing the manuscript, and AT helped in preparing the manuscript.

\section{Compliance with ethical standards}

Conflict of interest The authors declare that they have no conflict of interest.

Open Access This article is distributed under the terms of the Creative Commons Attribution 4.0 International License (http://creativeco mmons.org/licenses/by/4.0/), which permits unrestricted use, distribution, and reproduction in any medium, provided you give appropriate credit to the original author(s) and the source, provide a link to the Creative Commons license, and indicate if changes were made. 


\section{References}

Alam MM, Nahar K, Hasanuzzaman M, Fujita M (2014) Exogenous jasmonic acid modulates the physiology, antioxidant defense and glyoxalase systems in imparting drought stress tolerance in different Brassica species. Plant Biotechnol Rep 8:279-293. https://doi.org/10.1007/s11816-014-0321-8

Ara H, Jaiswal U, Jaiswal VS (1999) Germination and plantlet regeneration from encapsulated somatic embryo of mango (Mangifera indica L.). Plant Cell Rep 19:166-170. https://doi.org/10.1007/ s002990050728

Ayala A, Muñoz MF, Argüelles S (2014) Lipid peroxidation: production, metabolism, and signaling mechanisms of malondialdehyde and 4-hydroksy-2-nonenal. Oxid Med Cell Longev 2014:360438. https://doi.org/10.1155/2014/360438

Bandurska H, Stroiński A, Kubiś J (2003) The effect of jasmonic acid on the accumulation of ABA, proline and spermidine and its influence on membrane injury under water deficit in two barley genotypes. Acta Physiol Plant 25:279-285. https://doi. org/10.1007/s11738-003-0009-0

Bates LS, Waldren RP, Teare ID (1973) Rapie determination of free proline for water-stress studies. Plant Soil 39:205-207. https:// doi.org/10.1007/BF00018060

Carvajal F, Palma F, Jamilena M, Garrido D (2015) Preconditioning treatment induces chilling tolerance in zucchini fruit improving different physiological mechanisms against cold injury. Ann Appl Biol 166:340-354. https://doi.org/10.1111/aab.12189

Chen CT, Chou CM, Kao CH (1994) Methyl jasmonate induces the accumulation of putrescine but not proline in detached rice leaves. J Plant Physiol 143:119-124. https://doi.org/10.1016/ S0176-1617(11)82107-3

Cho K, Agrawal GK, Shibato J, Jung YH, Kim YK, Nahm BH, Jwa NS, Tamogami S, Han O, Kohda K, Iwahashi H, Rakwal R (2007) Survey of differentially expressed proteins and genes in jasmonic acid treated rice seedling shoot and root at the proteomic and transcriptomics levels. J Proteome Res 6:3581-3603. https://doi.org/10.1021/pr070358v

Dolcet-Sanjuan R, Claveria E (1995) Improved shoot-tip micropropagation of Pistacia vera $\mathrm{L}$. and the beneficial effects of methyl jasmonate. J Am Soc Hortic Sci 120:938-942

Du H, Liu H, Xiong L (2013) Endogenous auxin and jasmonic acid levels are differentially modulated by abiotic stresses in rice. Front Plant Sci 4:397. https://doi.org/10.3389/fpls.2013.00397

Ghasemi Pirbalouti A, Sajjadi SE, Parang K (2014) A review (research and patent) on jasmonic acid and its derivatives. Arch Pharm Chem Life Sci 347:229-239. https://doi.org/10.1002/ ardp.201300287

González-Aguilar GA, Fortiz J, Cruz R, Baez R, Wang CY (2000) Methyl jasmonate reduces chilling injury and maintains postharvest quality of mango fruit. J Agric Food Chem 48:515-519. https://doi.org/10.1021/jf9902806

Gutierrez L, Mongelard G, Floková K et al (2012) Auxin controls Arabidopsis adventitious root initiation by regulating jasmonic acid homeostasis. Plant Cell 24:2515-2527. https://doi. org/10.1105/tpc.112.099119

Hayat S, Hayat Q, Alyemeni MN, Wani AS, Pichtel J, Ahmad A (2012) Role of proline dunder changing environments. Plant Signal Behav 7:1456-1466. https://doi.org/10.4161/psb.21949

Hu Y, Jiang L, Wang F, Yu D (2013) Jasmonate regulates the inducer of CBF expression-C-repeat binding factor/DRE binding factor 1 cascade and freezing tolerance in Arabidopsis. Plant Cell 25:2907-2924. https://doi.org/10.1105/tpc.113.112631

Kamata T, Uemura M (2004) Solute accumulation in heat seedlings during cold acclimation: contribution to increased freezing tolerance. Cryo Lett 25:311-322
Kamińska M, Skrzypek E, Wilmowicz E, Tretyn A, Trejgell A (2016) Effect of light condition and ABA on cold storage and post-storage propagation of Taraxacum pieninicum. Plant Cell Tissue Organ Cult 127:25-34. https://doi.org/10.1007/s1124 0-016-1026-1

Kamińska M, Gołębiewski M, Tretyn A, Trejgell A (2018) Efficient long-term conservation of Taraxacum pieninicum synthetic seeds in slow growth conditions. Plant Cell Tissue Organ Cult 132:469 478. https://doi.org/10.1007/s11240-017-1343-Z

Kaplan F, Kopka J, Sung DY, Zhao W, Popp M, Porat R, Guy CL (2007) Transcript and metabolite profiling during cold acclimation of Arabidopsis reveals an intricate relationship of cold-regulated gene expression with modifications in metabolite content. Plant $\mathbf{J}$ 50:967-981. https://doi.org/10.1111/j.1365-313X.2007.03100.x

Kishor PBK, Sangam S, Amrutha RN, Laxmi PS, Naidu KR, Rao KRSS, Rao S, Reddy KJ, Theriappan P, Sreenivasulu N (2005) Regulation of proline biosynthesis, degradation, uptake and transport in higher plants: Its implications in plant growth and abiotic stress tolerance. Curr Sci 88:424-438

Koo AJ (2017) Metabolism of the plant hormone jasmonate: a sentinel for tissue damage and master regulator of stress response. Phytochem Rev 17:51-80. https://doi.org/10.1007/s11101-017-9510-8

Kosová K, Prášil IT, Vítámvás P, Dobrev P, Motyka V, Floková K, Novák O, Turečková V, Rolčik J, Pešek B, Trávničková A, Gaudinová A, Galiba G, Janda T, Vlasáková E, Prášilová P, Vanková $\mathrm{R}$ (2012) Complex phytohormone responses during the cold acclimation of two wheat cultivars differing in cold tolerance, winter Samanta and spring Sandra. J Plant Physiol 169:567-576. https ://doi.org/10.1016/j.jplph.2011

Li P, Zheng X, Liu Y, Zhu Y (2014) Pre-storage application of oxalic acid alleviates chilling injury in mango fruit by modulating proline metabolism and energy status under chilling stress. Food Chem 142:72-78. https://doi.org/10.1016/j.foodchem.2013.06.132

Martín-Closas L, Sol S, Pelacho AM (2000) Potential application of jasmonic acid for Solanum tuberosum micropropagation. Acta Hortic 52:127-133. https://doi.org/10.17660/ActaHortic .2000 .520 .13

Maslenkova LT, Miteva TS, Popova LP (1992) Changes in the polypeptide patterns of barley seedlings exposed to jasmonic acid and salinity. Plant Physiol 98:700-707. https://doi.org/10.1104/ pp.98.2.700

Miyamoto K, Oka M, Ueda J (1997) Update on the possible mode of action of the jasmonates: focus on the metabolism of cell wall polysaccharides in relation to growth and development. Physiol Plant 100:631-638. https://doi.org/10.1111/j.1399-3054.1997. tb03069.x

Morquecho-Contreras A, Méndez-Bravo A, Pelagio-Flores R, RayaGonzález J, Ortíz-Castro R, López-Bucio J (2010) Characterization of $d r r l$, an Alkamide-Resistant mutant of Arabidopsis, reveals an important role for small lipid amides in lateral root development and plant senescence. Plant Physiol 152:1659-1673

Piotrowska A, Bajguz A, Czerpak R, Kot K (2010) Changes in the growth, chemical composition, and antioxidant activity in the aquatic plant Wollfia arrhiza (L.) Wimm. (Lemnaceae) exposed to jasmonic acid. J Plant Growth Regul 29:53-62. https://doi. org/10.1007/s00344-009-9113-8

Qiu Z, Guo J, Zhu A, Zhang L, Zhang M (2014) Exogenous jasmonic acid can enhance tolerance of wheat seedling to salt stress. Ecotoxicol Environ Saf 104:202-208. https://doi.org/10.1016/j.ecoen v.2014.03.014

Ravnikar MJ, Rode N, Gogala N, Benedicic D (1990) Regulation of organogenesis with jasmonic acid. Acta Hort 280:169-172. https ://doi.org/10.17660/ActaHortic.1990.280.29

Ravnikar M, Vilhar B, Gogala N (1992) Stimulatory effects of jasmonic acid on potato stem node and protoplast culture. J Plant Growth Regul 11:29-33. https://doi.org/10.1007/BF00193840 
Ravnikar M, Žel J, Plaper I, Špacapan A (1993) Jasmonic acid stimulates shoot and bulb formation of garlic in vitro. J Plant Growth Regul 12:73-77. https://doi.org/10.1007/BF00193236

Raya-González J, Pelagio-Flores R, López-Bucio J (2012) The jasmonate receptor COI1 play a role in jasmonate-induced lateral root formation and lateral root positioning in Arabidopsis thaliana. J Plant Physiol 169:1348-1358. https://doi.org/10.1016/j. jplph.2012.05.002

Rihan HZ, Kareem F, El-Mahrouk ME, Fuller MP (2017) Artificial seeds (principle, aspects and applications. Agronomy 7:71. https ://doi.org/10.3390/agronomy7040071

Rooy SSB, Salekdeh GH, Ghabooli M, Gholami M, Karimi R (2017) Cold-induced physiological and biochemical responses of three grapevine cultivars differing in cold tolerance. Acta Physiol Plant 39:264. https://doi.org/10.1007/s11738-017-2561-z

Ružić D, Vujović T, Cerović R (2013) Effect of jasmonic acid on in vitro multiplication of low vigorous pear and cherry rootstocks. Fruit Growing Res XXIX:106-112

Schomer C, Palatnik JF, Aggarwal P, Chételat A, Cubas P, Farmer E, Nath U, Weigel D (2008) Control of jasmonate biosyntesis and senescence by miR319 Target. PLoS Biol 6(9):e230. https://doi. org/10.1371/journal.pbio.0060230

Sembdner G, Parthier B (1993) The biochemistry and the physiological and molecular actions of jasmonates. Annu Rev Plant Physiol Plant Mol Biol 44:569-589. https://doi.org/10.1146/annur ev.pp.44.060193.003033

Shan T, Jin P, Zhang Y, Huang Y, Wang X, Zheng Y (2016) Exogenous glycine betaine treatment enhances chilling tolerance of peach fruit during cold storage. Postharvest Biol Technol 114:104-110. https://doi.org/10.1016/j.postharvbio.2015.12.005

Siboza XI, Bertling I, Odindo AO (2014) Salicylic acid and methyl jasmonate improve chilling tolerance in cold-stored lemon fruit (Citrus limon). J Plant Physiol 171:1722-1731. https://doi. org/10.1016/j.jplph.2014.05.012
Song SY, Chen Y, Chen J, Dai XY, Zhang WH (2011) Physiological mechanisms underlying OsNAC5-dependent tolerance of rice plants to abiotic stress. Planta 234:331-345. https://doi. org/10.1007/s00425-011-1403-2

Sun J, Xu Y, Ye S et al (2009) Arabidopsis ASAl is important for jamonate-mediated regulation of auxin biosynthesis and transport during lateral root formation. Plant Cell 21:1495-1511. https:// doi.org/10.1105/tpc.108.064303

Theocharis A, Clément C, Barka EA (2012) Physiological and molecular changes in plants grown at low temperatures. Planta 235:10911105. https://doi.org/10.1007/s00425-012-1641-y

Toro FJ, Martín-Closas L, Pelacho AM (2003) Jasmonates promote cabbage (Brassica oleracea L. var Capitata L.) root and shoot development. Plant Soil 255:77-83. https://doi. org/10.1023/A:1026104210974

Trejgell A, Chernetskyy M, Podlasiak J, Tretyn A (2013) An efficient system for regenerating Taraxacum pieninicum Pawt. from seedling explants. Acta Biol Cracov Bot 55:73-79. https://doi. org/10.2478/abcsb-2013-00013

Wang S, Ichii M, Taketa S, Xu L, Xia K, Zhou X (2002) Lateral root formation in rice (Oryza sativa): promotion effect of jasmonic acid. J Plant Physiol 159:827-832. https://doi. org/10.1078/0176-1617-00825

Wasternack C (2014) Action of jasmonates in plant stress responses and development-applied aspects. Biotechnol Adv 32:31-39. https://doi.org/10.1016/j.biotechadv.2013.09.009

Woodward AW, Bartel B (2005) Auxin: regulation, action, and interaction. Ann Bot 95:707-735. https://doi.org/10.1093/aob/mci083

Yadav SK (2010) Cold stress tolerance mechanisms in plants. A review. Agron Sustain Dev 30:515-527. https://doi.org/10.1051/ agro/2009050

You J, Chan Z (2015) ROS regulation during abiotic stress responses in crop plants. Front Plant Sci 6:1092. https://doi.org/10.3389/ fpls.2015.01092 